\title{
Aplikasi Sistem Informasi Social Media Advertise Maintenance Menggunakan Pendekatan Object Oriented Methodology
}

\author{
Sri Rahayu*1, Ryanthika Serliyanthi Setyaningrum ${ }^{2}$, Yuni Kristina Dewi ${ }^{3}$ \\ ${ }^{1}$ Program Studi Teknologi Informatika Universitas Raharja \\ ${ }^{2,3}$ Program Studi Sistem Informasi Universitas Raharja \\ Email: *11 srirahayu@ raharja.info, ${ }^{2}$ ryanthika@ raharja.info, ${ }^{3}$ yuni.kristina@ raharja.info
}

\begin{abstract}
Abstrak
Sistem Informasi yang dibangun dalam bentuk media sosial dan internet membuat kita mampu melakukan berbagai kegiatan tanpa harus tatap muka. Media sosial saat ini menjadi daya tarik utama bagi masyarakat untuk berkomunikasi dan mencari informasi dengan cepat. Inilah peluang besar bagi perusahaan untuk menjangkau dan meluaskan pasarnya. Dengan Sistem Informasi yang dibangun dalam bentuk media sosial dan internet segala kendala baik jarak maupun biaya yang tinggi dapat ditekan dan komunikasi dapat dilakukan dengan efektif. Selama ini PT. Red Eye Utama melakukan pemasaran melalui iklan radio, Koran/baliho, hal inilah yang menjadi timbulnya permasalahan, karena terbatasnya ruang dan waktu, serta biaya yang tinggi untuk melakukan semua proses tersebut. Proses negosisi antara perusahaan dengan customer menjadi salah satu hambatan yang berpengaruh pada pelayanan perusahaan kepada customer. Maka dari itu salah satu solusi untuk permasalahan pada sistem ini adalah dengan membangun Sistem Informasi Social Media Advertise Maintenance. Dengan menggunakan analisis metode PIECES untuk perbaikan-perbaikan berdasarkan indicator performance, indicator information, indicator economic, indicator control, indicator efficiency dan indicator services. Untuk membuat rancangan sistem barunya, digunakan pemodelan yang berorientasi objek yaitu UML (Unified Modeling Language) yang merupakan tools yang tepat untuk digunakan dalam menggambarkan rancangan sistem yang akan dibuat sesuai kebutuhan User.
\end{abstract}

Kata Kunci : Social Media Advertise, Pemasaran Digital, Object Oriented Methodology.

\begin{abstract}
Information systems built in the form of social media and the internet make us able to carry out various activities without having to meet face to face. Social media is currently the main attraction for people to communicate and find information quickly. This is a great opportunity for companies to reach and expand their market. With an information system built in the form of social media and the internet, all obstacles, both distance and high costs, can be suppressed and communication can be carried out effectively. So far, PT. Red Eye Utama conducts marketing through radio advertisements, newspapers / billboards, this is what causes problems, due to limited space and time, as well as high costs to carry out all these processes. The negotiation process between the company and the customer is one of the obstacles that affects the company's service to customers. Therefore, one solution to the problems in this system is to build a Social Media Advertise Maintenance Information System. By using PIECES method analysis for improvements based on performance indicators, indicator information, economic indicators, control indicators, efficiency indicators and service indicators. To design the new system, object-oriented modeling is used, namely UML (Unified Modeling Language) which is the right tool to use in describing the system design that will be made according to User needs.
\end{abstract}

Keywords: Social Media Advertise, Digital Marketing, Object Oriented Methodology. 


\title{
1. Pendahuluan
}

Sistem Informasi dan internet yang memadai kita mampu melakukan kegiatan-kegiatan tanpa harus tatap muka. Sebelumnya untuk dapat memasarkan sebuah produk atau pun jasa, sebagai penjual harus dapat menjangkau pembeli secara langsung dengan biaya yang tinggi karena harus melewati tahap bertemunya penjual dan pembeli secara fisik. Dengan Sistem Informasi dan internet segala kendala baik jarak maupun biaya yang tinggi dapat ditekan dan komunikasi dapat dengan mudah dilakukan dengan efektif. Media sosial menjadi daya tarik utama bagi masyarakat untuk menghabiskan waktu mereka. Inilah peluang besar bagi penjual atau sebuah perusahaan untuk menjangkau dan meluaskan pasarnya. Maka baiknya jika sebuah perusahaan menggunakan media sosial sebagai akses untuk memasarkan produknya. Hal ini dikarenakan pemasaran pada media sosial tidak tampak seperti iklan pada umumnya. Masyarakat disajikan iklan layaknya sebuah informasi yang lumrah pada umumnya ada pada media sosial. PT. Red Eye Group adalah perusahaan yang berdiri sejak tahun 2011 yang memiliki tujuan inti yaitu menjadi pemenang di hati setiap pelanggan. Dalam proses bisnisnya, Red Eye Group memiliki beberapa tim yang memiliki tugas dan tanggung jawab masing-masing. Digitize Team memberikan pelayan dari berbagai aspek pengiklanan di dunia digital mulai dari media publishing ads, creative content, web \& mobile development dan social media \& google ads. Kampanye terhadap produk atau jasa dapat tersampaikan lebih maksimal dengan menggunakan teknologi informasi, sosoal media dan strategi SEO (Search Engine Optimize), Digital Analytics System, Social Media Content Management dan Programing Development. PT. Red Eye Utama melakukan pemasaran melalui iklan radio, koran atau baliho, hal inilah yang menjadi timbulnya permasalahan, karena terbatasnya ruang dan waktu, serta biaya yang tinggi untuk melakukan semua proses tersebut. Proses negosiasi antara perusahaan dengan customer menjadi salah satu hambatan dari segi waktu yang cukup berpengaruh pada pelayanan perusahaan kepada customer maupun calon customer lainnya. PT. Red Eye Utama menyadari potensi Digital Marketing sejak lama dimana proses pemasaran produk dilakukan secara digital melalui media sosial dan mesin pencarian dibanding melalui iklan radio, koran atau baliho. Beriklan dimedia sosial menjadi sangat efektif dan efisien menjangkau pasar tanpa terbatas lokasi, jarak mauapun waktu karena bisa dilakukan kapan saja dan dimana saja sesuai dengan prinsip internet yang berbasis online. Namun, kemudahan ini juga berarti memungkinkan customer dengan berbagai kebutuhan untuk beriklan secara digital mulai dari kecil, menengah hingga atas. Dengan meluasnya informasi kepada customer bahwa kami dapat melayani berbagai kebutuhan pengiklan digital mereka, membuat pihak pengiklan merasa kuwalahan jika semua customer ditangani dengan persuasif dan penjelasan produk secara langsung. Kelemahan yang ada pada sistem saat ini adalah proses penerimaan order yang tidak efektif dan efisien karena membutuhkan janji temu yang menyita waktu Digitize Time. Dimana waktu tersebut dapat dimanfaatkan untuk menerima order project lainnya. Hal ini menjadi permasalahan yang cukup besar saat ini bagi Digitize Team, mengakibatkan tidak memaksimalkan jumlah pelayanan yang masuk pada perusahaan dan pelayanan menjadi lambat. Melihat hal tersebut, sebuah ruang atau tempat untuk pihak pembuat iklan menawarkan produk mereka dirasa perlu untuk demi proses bisnis yang lebih efektif dan efisien. Melalui media periklanan ini juga akan ditampilkan paket-paket produk dengan berbagai jenjang harga dan kebutuhan customer dengan harapan, customer dapat lebih mudah memutuskan jenis iklan yang ingin digunakan secara mandiri baik target pasar hingga budget yang sesuai dengan kemampuan customer dengan langkah sederhana yang dapat mewakali beberapa platform sosial media.

\section{TINJAUAN PUSTAKA}

\author{
Social Media Advertising
}


Definisi Social Media menurut Nasrullah (2015:11) adalah medium di internet yang memungkinkan pengguna merepresentasikan dirinya maupun berinteraksi, bekerja sama, berbagi, berkomunikasi dengan pengguna lain dan membentuk ikatan sosial secara virtual. Pengertian dari social media advertising yaitu sebuah upaya yang dilakukan pemasar dalam menyampaikan pesan (ide, gagasan, nilai) kepada konsumen dengan berperan langsung dalam ikatan sosial masyarakat pada medium internet, sehingga dapat berinteraksi, berkomunikasi dan berkolaborasi dengan calon konsumen sasaran dan seacara aktif mempromosikan produk atau jasa. [1]

Definisi Advertising disampaikan oleh Ario dkk (2016) mengutip dari Moriarty (2009:6) bahwa advertising adalah komunikasi pemasaran yang merupakan istilah umum yang mengacu kepada semua bentuk teknik komunikasi yang digunakan pemasar untuk menjangkau konsumennya dan menyampaikan pesannya.[2][3]

\section{Digital Marketing}

Digital Marketing menurut Prabowo (2018) adalah Membantu sebuah perusahaan dalam mempromosikan dan memasarkan produk maupun jasa yang mereka punya. Digital Marketing juga dapat membuat atau membuka pasar-pasar baru yang sebelunya tertutup karena adanya keterbatasan waktu, cara komunikasi, maupun jarak.[4]

Sementara itu, penelitian Leisander dan Dharmayanti (2017) mengemukakan bahwa digital marketing memang berdampak secara langsung terhadap kinerja industri, di mana semakin tinggi digital marketing yang diterapkan oleh suatu industri maka semakin tinggi pula kinerja industri, khususnya kinerja pemasaran.[5]

\section{UML (Unified Modeling Language)}

Menurut Ade Hendini (2016) UML adalah bahasa spesifikasi standar yang digunakan untuk mendokumentasikan, menentukan dan membangun perangkat lunak.[6]

Menurut Maimunah dkk (2017) yang disampaikan oleh Tamara Samudra (2019) "UML (Unified Modeling Language) adalah perangkat lunak yang memiliki paradigma "berorientasi objek". Pemodelan (modeling) sebenarnya digunakan untuk menyederhanakan masalah yang kompleks sedemikian rupa sehingga lebih mudah dipelajari dan dipahami”.[7][8]

\section{Metode Penelitian}

\section{Metode Pengumpulan Data}

Untuk pengumpulan data sendiri, penulis menggunakan beberapa metode, antara lain :

- Metode Observasi

Metode dimana peneliti harus meninjau apa yang diteliti.

Penulis melakukan pengamatan langsung pada sistem yang berjalan di PT. Red Eye Utama dengan terlibat dalam proses bisnis yang ada. Lalu dari pengamatan tersebut, penulis mengumpulkan data yang diperlukan untuk dianalisis agar dapat mengembangkan sistem tersebut.

- Metode Wawancara

Melalui proses wawancara, penulis melakukan Tanya jawab dengan narasumber, salah satunya adalah digital director pada PT. Red Eye Utama yang merupakan tempatpenelitian berlangsung. Metode ini dilakukan agar mendapatkan data yang relevan sesuai kebutuhan sistem. 


\section{Metode Analisa}

Metode PIECES merupakan metode analisis yang digunakan untuk mendapatkan inti permasalahan yang lebih detail. Dalam menganalisis sebuah sistem, biasanya akan dilakukan terhadap beberapa aspek antara lain adalah :

\section{a. Performance (kinerja)}

Dimana memiliki peran penting dalam menilai apakah suatu proses atau prosedur yang ada masih memungkinkan untuk meningkatkan kinerjanya dan untuk melihat sejauh mana dan seberapa andal suatu sistem informasi dalam memproses untuk menghasilkan tujuan yang diinginkan. Pada PT. Red Eye Utama saat ini, kinerja sistem kurang efisien, karena membutuhkan waktu yang cukup lama dalam prosesnya, mulai dari pendaftaran, pertemuan langsung, negosiasi, kesepakatan projek dan seterusnya.

\section{b. Information (informasi)}

Apakah prosedur yang ada dapat diperbaiki sehingga kualitas informasi yang dihasilkan semakin baik. Informasi yang disajikan harus benar-benar bernilai guna. Pada PT.Red Eye Utama saat ini, penerimaan informasi sangat lambat, karena penyampaian informasi sangat terbatas, jika klien tidak langsung datang ke perusahaan.

\section{c. Economic (ekonomi)}

Apakah prosedur saat ini dapat diperbaiki (nilai penggunaannya) atau mengurangi biaya pelaksanaannya. Proses pembiayaan saat ini menjadi tidak ekonomis, hal tersebut dikarenakan pihak klien dan PT. Red Eye Utama harus beberapa kali mengadakan janji bertemu untuk sampai pada kesepakatan.

\section{d. Control (pengendalian)}

Apakah prosedur yang ada sekarang dapat diperbaiki sehingga kualitas kontrolnya lebih baik dan kemampuan mendeteksi kesalahan / fraud semakin baik. Karena kompleksitas proses yang terjadi antara PT. Red Eye Utama dan klien sehingga terjadi kerumitan juga pada control kerja begitu pula dengan biaya.

\section{e. Efficiency (efisiensi)}

Apakah prosedur yang ada masih dapat ditingkatkan, untuk mencapai peningkatan efisiensi operasi dan harus lebih unggul dari sistem manual. Banyaknya waktu dan biaya yang dikeluarkan, sistem yang saat ini berjalan dikategorikan tidak efisien.

\section{f. Service (layanan)}

Apakah prosedur yang ada dapat ditingkatkan kemampuannya untuk mencapai kualitas layanan yang lebih baik. Dikarenakan lamanya waktu proses kesepakatan, jumlah klien yang cukup banyak, sehingga pemberian layanan kepada semua klien tidak bisa dilakukan dengan maksimal.

\section{Hasil Dan Pembahasan}

\section{Diagram Hasil Analisa Sistem}

Digitize Team sudah menjadi Google Advertising Certified Partner yang membantu banyak merek dan perusahaan untuk meningkatkan eksistensi mereka di dunia digital dengan memanfaatkan perkembangan teknologi dan media sosial untuk memasarkan produk sesuai pesanan pelanggan. Menggunakan metode SEO (Search Engine Optimize), Digital Analytics System, Social Media Content Management dan Programming Development, kampanye 
terhadap produk atau jasa yang dipesan oleh pelanggan dapat tersampaikan dengan lebih maksimal. Penulis mengangkat proses penanganan pesanan yang sedang berjalan pada sistem saat ini. Setelah tim Business Development mendapat proyek, tim tersebut menghubungi client dan membuat janji temu untuk memaparkan apa kebutuhan client. Setelah konsep terbentuk, tim Business Development menindaklanjuti konsep tersebut dengan melakukan diskusi bersama tim internal. Selanjutnya tim internal menyiapkan presentasi proposal dan account team melakukan negosiasi harga proyek. Hingga semua ketentuan, harga, kontrak dan perjanjian lainnya telah disepakati, serta proses pembayaran pihak klien sudah diselesaikan, barulah proyek dijalankan.

Kompleksitas proses yang terjadi digambarkan pada UML Diagram yaitu Activity Diagram pada Gambar 1 dibawah ini :

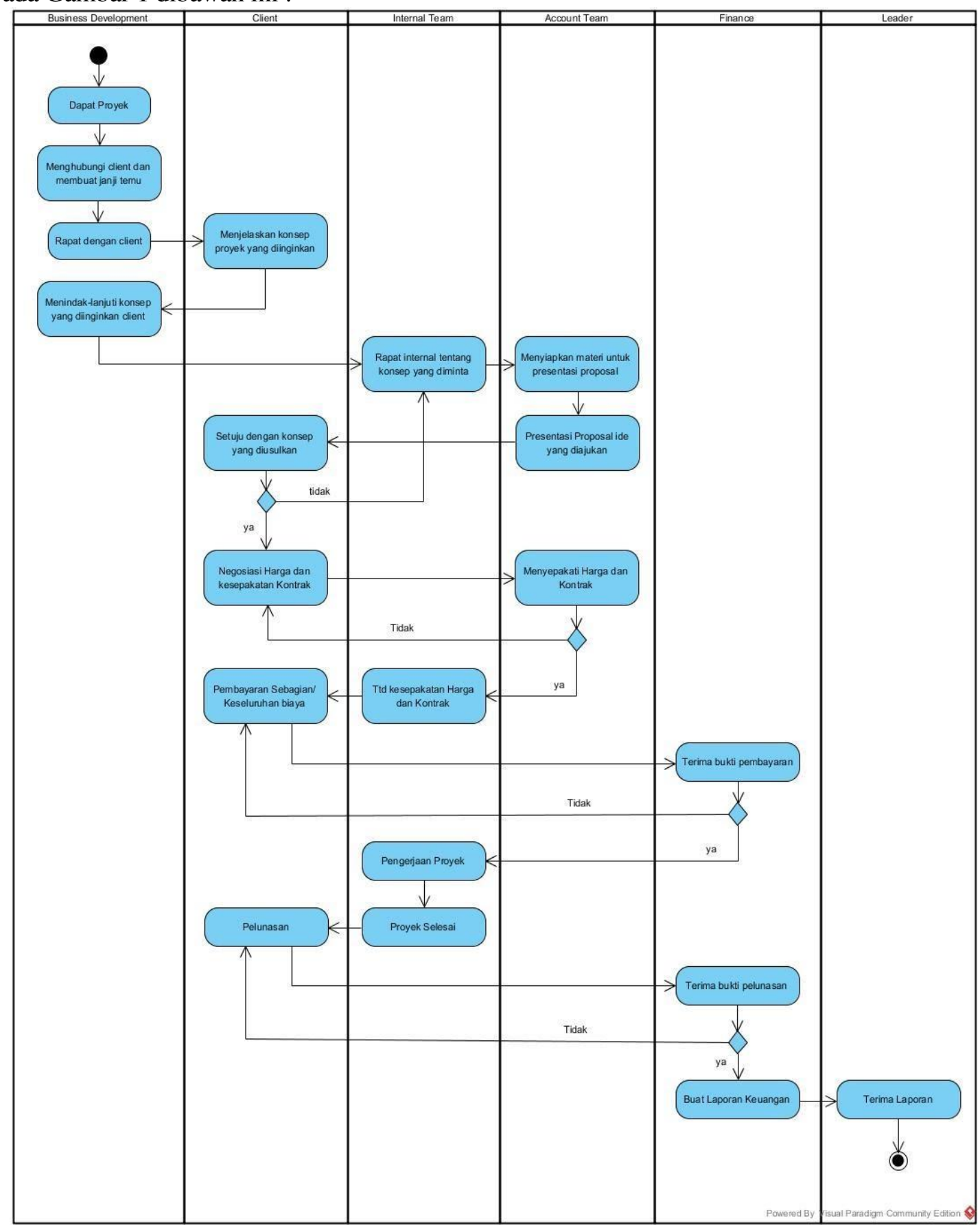

Gambar 1. Activity Diagram Saat Ini 


\section{Analisis PIECES pada sistem}

\section{Tabel 1. Analisa PIECES}

\begin{tabular}{|c|c|c|}
\hline Indikator & Sistem Berjalan & Sistem Usulan \\
\hline Performance & $\begin{array}{l}\text { dengan sistem yang ada, untuk mendapatkan } \\
\text { konsep yang klien inginkan, perusahaan harus } \\
\text { mengirim dua orang tenaga kerja dari Bussiness } \\
\text { team untuk mendiskuikannya. setelah itu butuh } \\
\text { response time satu minggu untuk menindaklajuti } \\
\text { konsep tersebut berupa presentasi produk yang } \\
\text { akan di eksekusi beserta negoisasi harga produk } \\
\text { tersebut dari Account team. Jika lancar maka } \\
\text { produk akan dieksekusi jika tidak akan ada } \\
\text { penyesuaian dengan tambahan response time satu } \\
\text { minggu. }\end{array}$ & $\begin{array}{l}\text { dengan menentukan sendiri paket dan } \\
\text { harga yang sudah ditawarkan, sistem } \\
\text { ini tidak memerhukan janji temu. } \\
\text { Sehingga bussiness team dapat fokus } \\
\text { dalam mengolah data agar sesuai } \\
\text { dengan keinginan client }\end{array}$ \\
\hline Information & $\begin{array}{l}\text { terkadang informasi yang disampaikan client tidak } \\
\text { relevan dengan tujuan untuk menghasilkan produk } \\
\text { ataupun penyampaian informasi tidak lengkap } \\
\text { sehingga saat datanya diolah, ternyata perh } \\
\text { penyesuaan kembali. }\end{array}$ & $\begin{array}{l}\text { client dapat menginput informasi } \\
\text { secara lengkap pada satu waktu saat } \\
\text { submit data. Sehingga produk jasa } \\
\text { yang diolah lebih cepat. }\end{array}$ \\
\hline Economic & $\begin{array}{l}\text { biaya tinggi untuk temu janji berulang dalam proses } \\
\text { order agar menyesuaikan kebutuhan klien }\end{array}$ & menghilangkan biaya perjalanan \\
\hline Control & $\begin{array}{l}\text { rekam jejak manual menjadikan kelemahan dalam } \\
\text { sistem ini, sehingga klient dapat berubdah-udah } \\
\text { dalam memberikan pernyataan yang dapat } \\
\text { melemahkan efisiensi pengerjaan produk }\end{array}$ & $\begin{array}{l}\text { rekam jejak digital yang masuk } \\
\text { menjadi dasar dalam mengolah data. }\end{array}$ \\
\hline Efficiency & $\begin{array}{l}\text { sangat tidak efisien karena janji temu fisik yang } \\
\text { behm tentu mengambil order pada perusahaan }\end{array}$ & $\begin{array}{l}\text { hanya client yang submit order yang } \\
\text { akan dilayani. }\end{array}$ \\
\hline Service & $\begin{array}{l}\text { service dengan janji temu meningkatkan bonding } \\
\text { dengan cleint, namun menurunkan efisiensi dalam } \\
\text { kinerja terlebih bagi cleint dengan nominal rendah } \\
\text { atau hanya ingin tahu saja (sebagai pembanding) } \\
\text { layanan dan harga yang perusahaan tawarkan }\end{array}$ & $\begin{array}{l}\text { tanpa janji temu, perusahaan masi } \\
\text { dapat memberikan layanan yang baik } \\
\text { dengan response time yang lebih } \\
\text { cepat dan ketersediaan layanan yang } \\
\text { lebih menjangkau. }\end{array}$ \\
\hline
\end{tabular}

\section{DIAGRAM RANCANGAN SISTEM}

\section{Use Case Diagram Rancangan Sistem}

UML digunakan sebagai alat permodelan utama yang berorientasi dengan objek untuk merancang sistem. Diagram yang gunakan untuk hasil rancangan kali ini adalah Use Case Diagram, Activity Diagram dan Sequence Diagram. Use Case Diagram digunakan dalam pemodelan rancangan sistem secara umum agar memudahkan setiap user yang terlibat dalam membaca kebutuhan user pada sistem serta implementasi dalam membangun aplikasinya. Dalam use case diagram hasil rancangan sistem, sistem yang dirancang menyediakan beberapa kemudahan fasilitas bagi user yang terlibat diantaranya Customer, Admin dan Leader pada perusahaan PT.Red eye Utama. Fasilitas bagi Customer tersebut adalah View Paket Socmed, Persetujuan Order, Pembayaran, Progress Order, yang dapat digunakan customer dalam memilih paket yang diinginkan dan sesuai dengan budget customer tanpa harus bernegosiasi panjang, hanya membutuhkan waktu yang singkat untuk memilih paket dan menyetujuinya.

Customer juga bisa mengecek secara real time progress order yang dilakukan, kemudian kemudahan fasilitas pihak Admin adalah Admin bisa segera melakukan analisa order hasil pilihan dari customer yang sudah masuk secara online, serta fasilitas Automatically Generate Report yang mempersingkat waktu Admin dalam menyiapkan laporan order kepada Leader. Perhatikan Lihat Gambar 2 dibawah ini : 


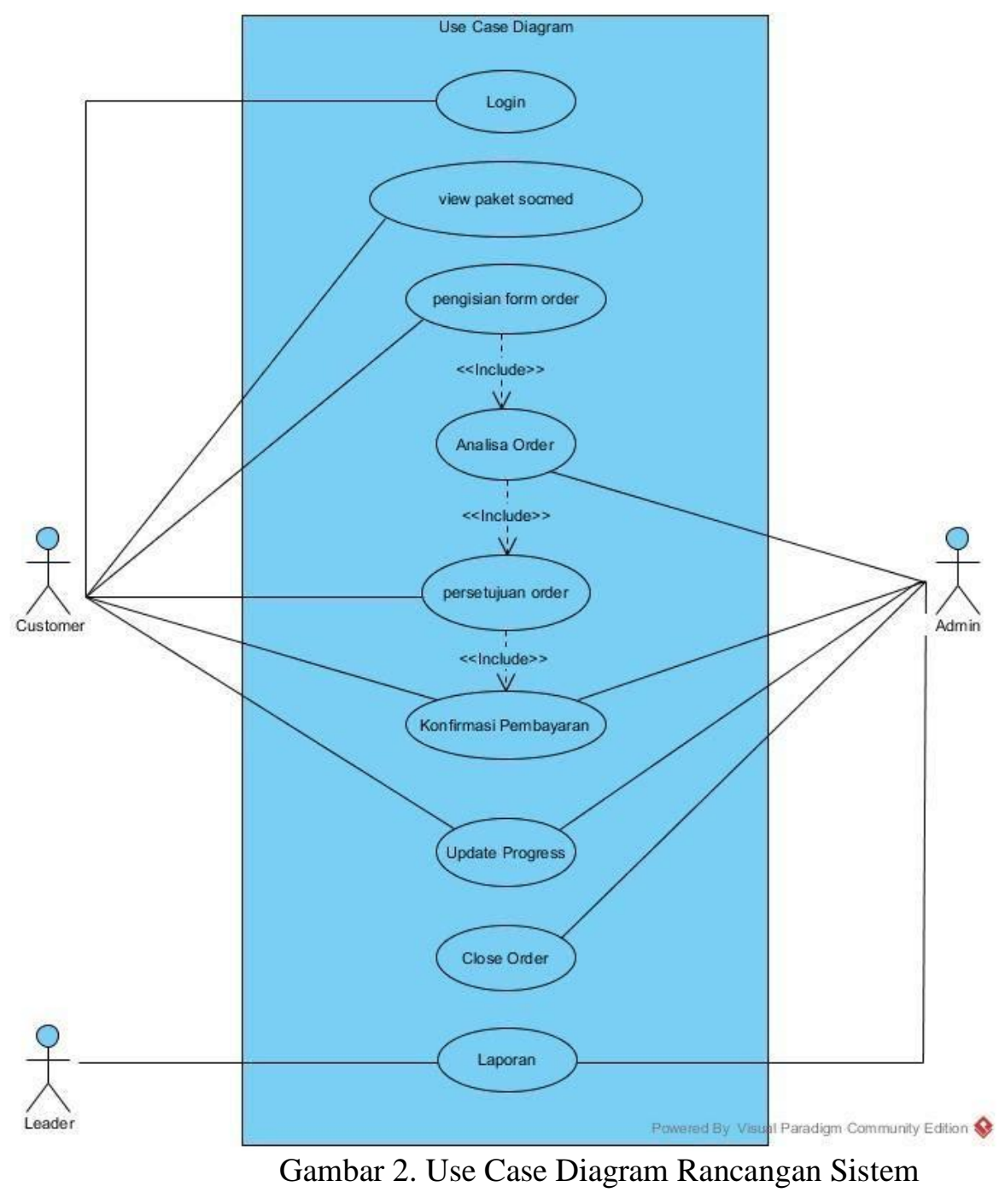

\section{Activity Diagram Rancangan Sistem}

Pada Gambar 3 dibawah, Customer akan diminta login terlebih dahulu dan melakukan register jika belum memiliki akun. Setelah terdaftar, customer dapat melihat paket layanan ikan pada social media yang tersedia dan memilih sebuah kebutuhan dengan cara mengisi form order. Form order yang disubmit akan diolah dan dianalisa agar menghasilkan output yang sesuai dengan input data. Jika customer setuju dengan output order dan biayanya, customer dapat memberikan persetujuan order dan menginfokan konfirmasi pembayaran.

Admin akan mengeksekusi produk jasa iklan pada media sosial sehingga proses order di-update menjadi status selesai. Admin akan memberika laporan kepada Leader. 


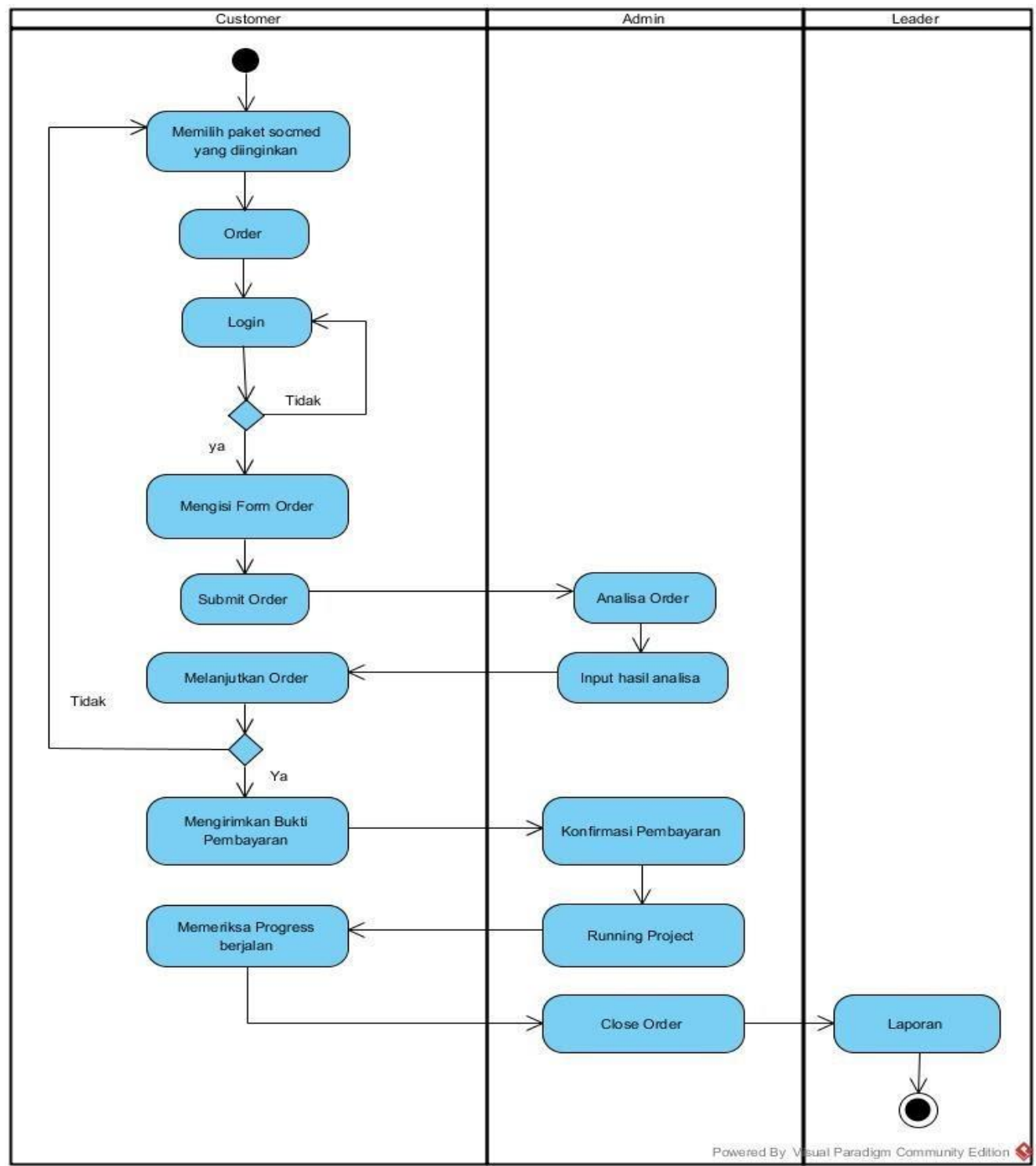

Gambar 3. Activity Diagram Rancangan Sistem

\section{Sequence Diagram Rancangan Sistem}

Sequence Diagram menggambarkan objek-objek yang akan menjadi kebutuhan user terhadap aplikasi sistem, agar sistem dibangun sesuai dengan user requirement. Berdasarkan fasilitas yang akan disediakan bagi semua user, maka disiapkan pula objek-objek yang akan digunakan dalam aplikasinya.

Terlihat pada Gambar 4 Sequence Diagram dibawah ini, terdapat beberapa objek yang akan digunakan antara lain Form Login, Data User, Laman Daftar Paket Socmed, Form Order, Form Analisa Admin, Form Pembayaran, Form Konfirmasi Pembayaran, Daftar dan status Order dan Laporan. 


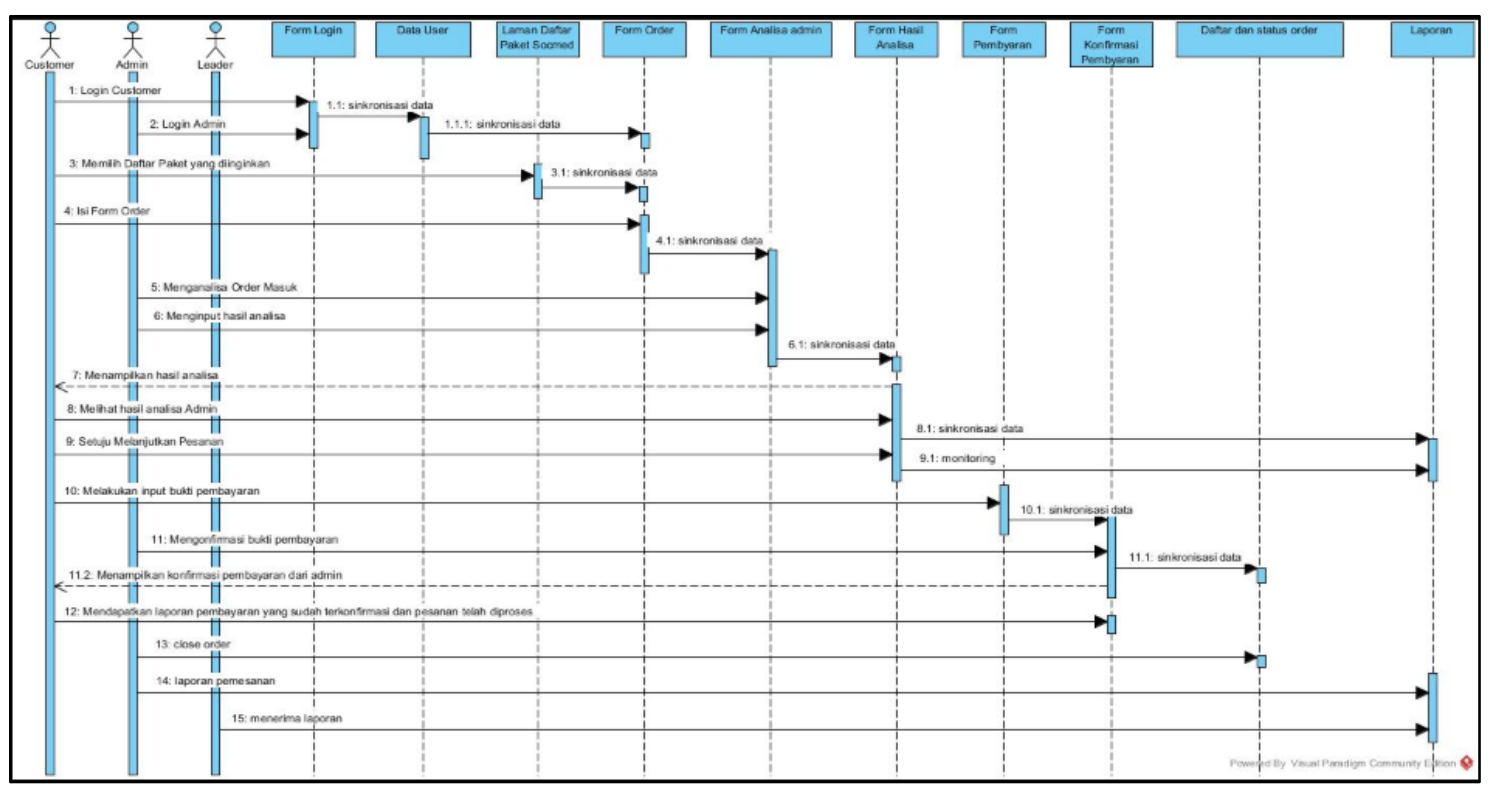

Gambar 4. Sequence Diagram Rancangan Sistem

\section{IMPLEMENTASI}

Hasil rancangan sistem kemudian diimplementasikan dalam bentuk aplikasi dengan tampilan beberapa objek aplikasi dibawah ini. Objek pertama pada Gambar 5 dibawah yaitu Daftar Harga Paket. Objek ini digunakan bagi customer untuk memilih paket yang diinginkan dan sesuai budget. Dengan memilih dan men-submit salah satu paket, artinya menyetujui tanpa perlu negosiasi panjang, tertera pada Gambar 6 yaitu Objek Form Order.

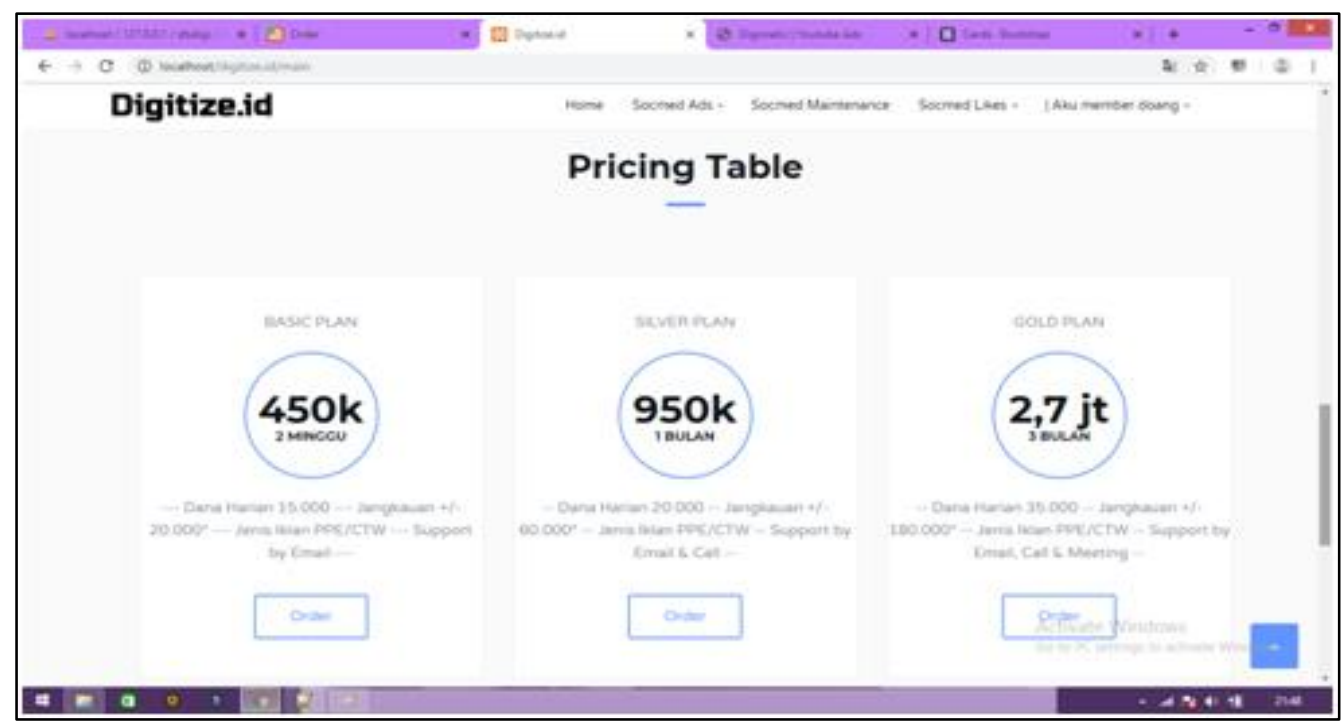

Gambar 5. Daftar Harga Paket 


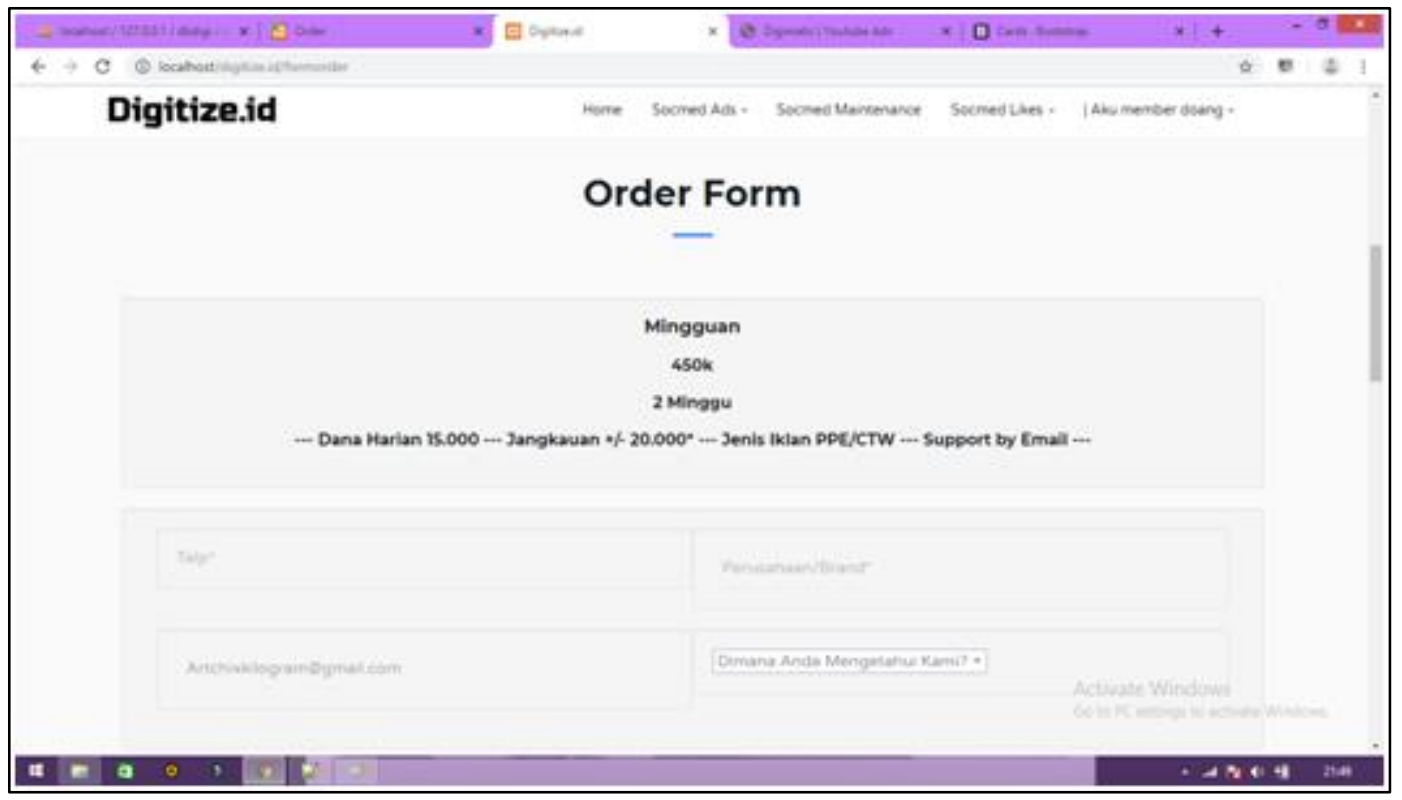

Gambar 6. Form Order

Submission yang dilakukan customer memudahkan pula bagi Admin untuk langsung melakukan analisa order untuk proses lebih lanjut (Gambar 7 dan Gambar 8).

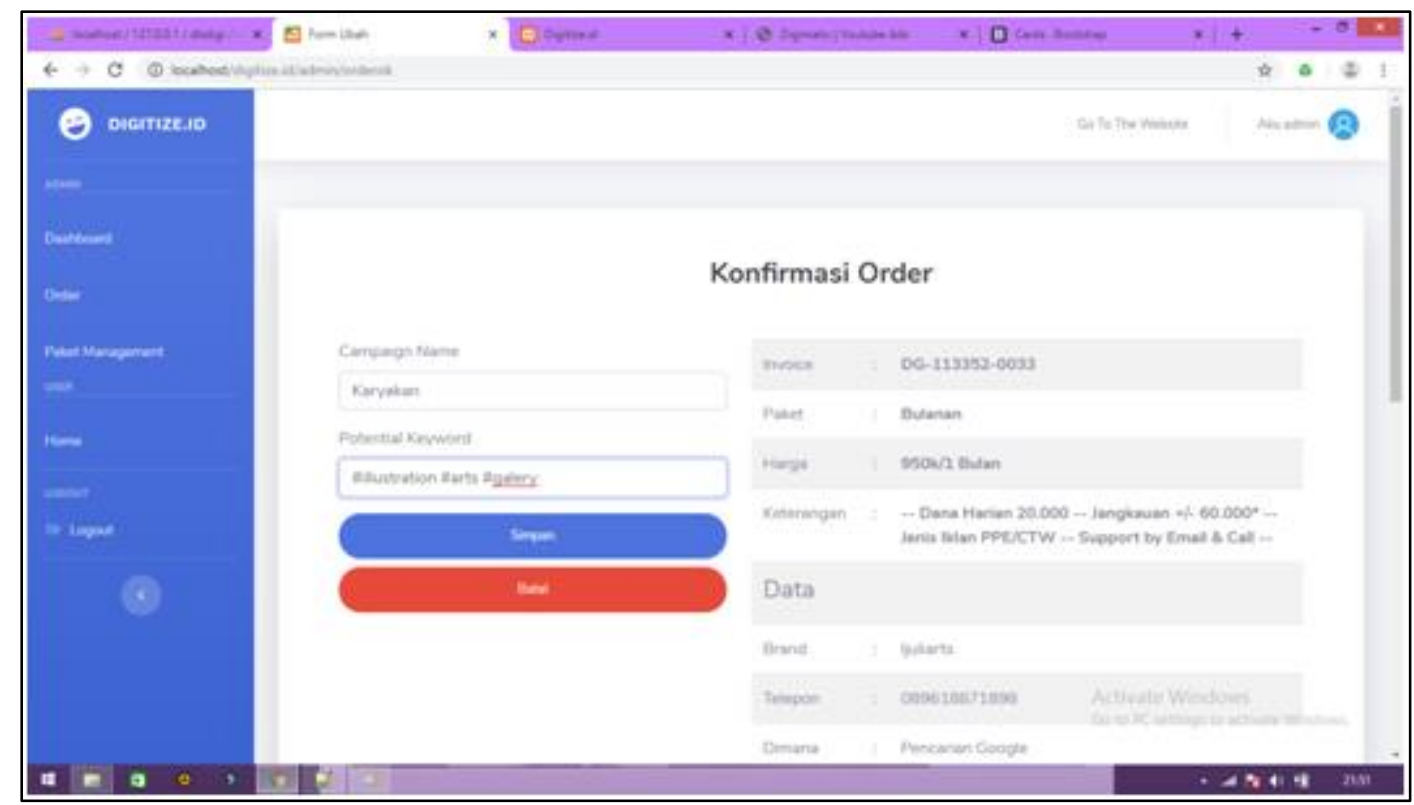

Gambar 7. Laman Konfirmasi Order 


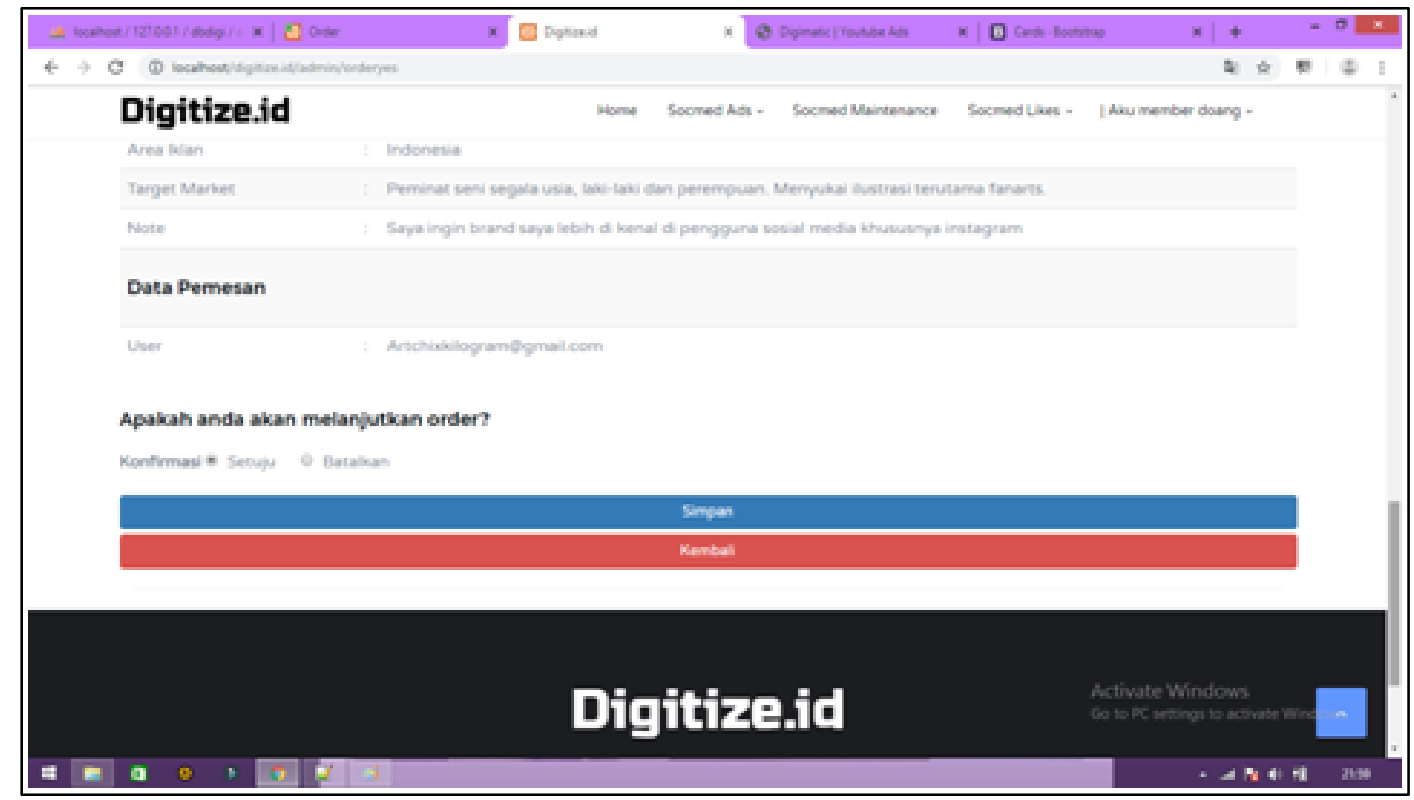

Gambar 8. Laman Hasil Analisa

Admin maupun customer dapat melihat setiap saat status order yang dilakukan oleh customer, seperti yang ditampilkan pada Gambar 9 dan Gambar 10.

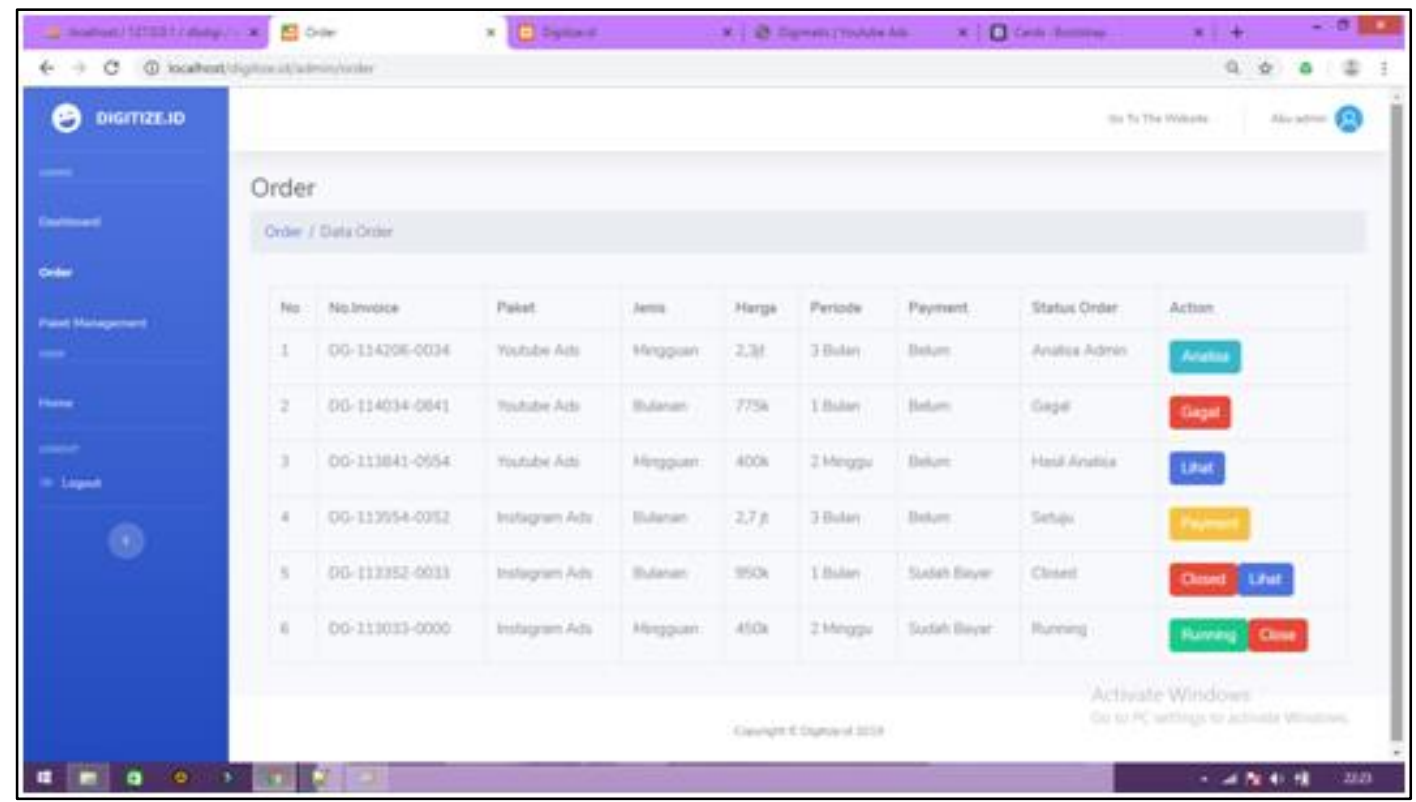

Gambar 9. Laman Admin Status Order 


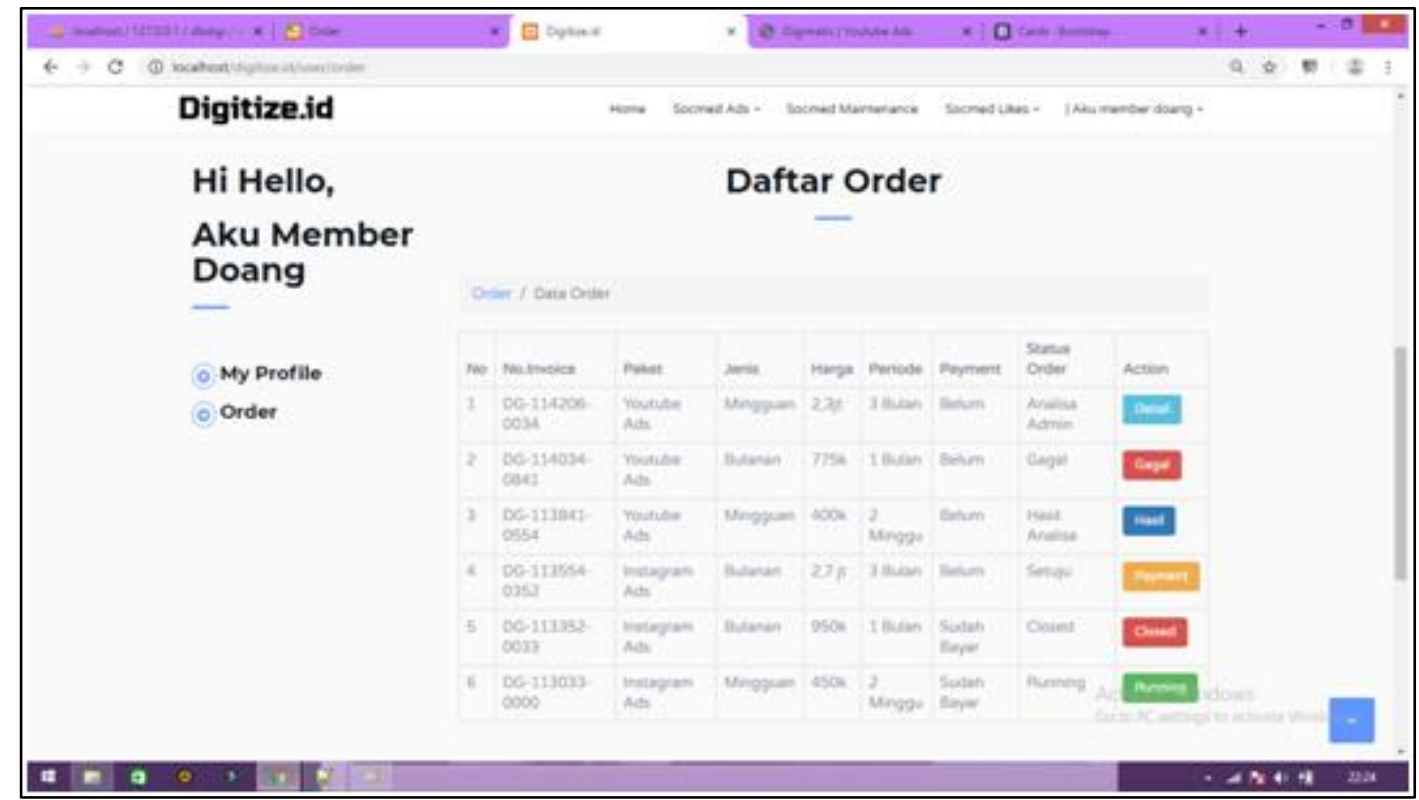

Gambar 10. Laman Customer Status Order

\section{Kesimpulan}

Penelitian ini menganalisis kinerja dari sistem yang berjalan dengan metode PIECES agar mengetahui secara spesifik kelemahan-kelemahan dari sistem yang saat ini berjalan, sehingga dapat ditarik kesimpulan bahwa sistem yang berjalan saat ini kurang efisien. Tidak semua perjanjian menghasilkan kesepakatan order dan terkadang ditemukan janji temu yang bernilai rendah tidak revelan dengan biaya perjalanan. Keinginan customer pun kadang berubah-ubah sehingga dapat memperlambat proses produksi jasa. Segala kelemahan tersebut menjadikan sistem yang berjalan tidak efektif dan efisien. Dengan mengimplementasikan Aplikasi Sistem Informasi Sosial Media Advertise Maintenance, maka PT. Red Eye Utama sebagai perusahaan penyedia layanan iklan menyediakan Sistem Informasi melalui media sosial, sehingga proses menjadi lebih efektif dan efisien.

\section{Saran}

Disarankan agar Aplikasi Sistem Informasi Sosial Media Advertise Maintenance yang telah dibuat dengan pendekatan Object Oriented Methodolgy ini dapat dikembangkan lebih lanjut lagi agar dapat memberikan manfaat dimasa yang akan dating, khususnya manfaat dalam bidang Social Media Advertise.

\section{Daftar Pustaka}

[1] Nasrullah, Rulli. 2015. Media Sosial. Bandung:Simbiosa Rekatama Media.

[2] Prakoso, Ario., dkk. 2016. "Pengaruh Social Media Advertising Terhadap Word of Mouth dan Dampaknya Pada Keputusan Pembelian (Survey pada Konsumen Cafe Mochimaco Malang yang Menggunakan Instagram)". Malang : Jurnal Administrasi Bisnis (JAB) Vol. 41 No.1 Desember 2016. 
[3] Moriarty, Sandra, Nancy Mitchell, dan William Wells. 2009. "Advertising”. Diterjemahkan oleh Tribowo B.S. 2011. Edisi 8. Jakarta: Kencana.

[4] Prabowo, W. A. 2018. Pengaruh Digital Marketing Terhadap Organizational Performance dengan Intellectual Capital dan Perceived Quality Sebagai Variabel Intervening Pada Industri Hotel Bintang Tiga Di Jawa Timur. Jurnal Manajemen Pemasaran, 12(2), 101112. https://doi.org/10.9744/pemasaran.12.2.101

[5] Liesander, Indra dan Diah Dharmayanti. (2017). Pengaruh Digital Marketing Terhadap Organizational Performance dengan Intellectual Capital dan Perceived Quality Sebagai Variabel Intervening pada Industri Hotel Bintang Lima di Jawa Timur, Jurnal Strategi Pemasaran, Vol.2, No.4, pp. 1-13.

[6] Hendini, Ade. 2016. "Permodelan UML Sistem Informasi Monitoring Penjualan Dan Stok Barang". Pontianak: Jurnal Khatulistiwa Infomatika. Vol.4, No. 2 Desember 2016 https://bit.ly/2KAxIsG.

[7] Maimunah dkk. 2017. "Aplikasi Sistem Order Online Berbasis Mobile Android Pada Outlet Pizza Hut Delivery”. Jurnal SEMNASTEKNOMEDIA Online Vol 5 No 1.

[8] Samudra, Tamara. 2019 "Aplikasi Pendaftaran Online Berbasis Website Pada SMK Pena Nusantara". Tangerang : Universitas Raharja. 